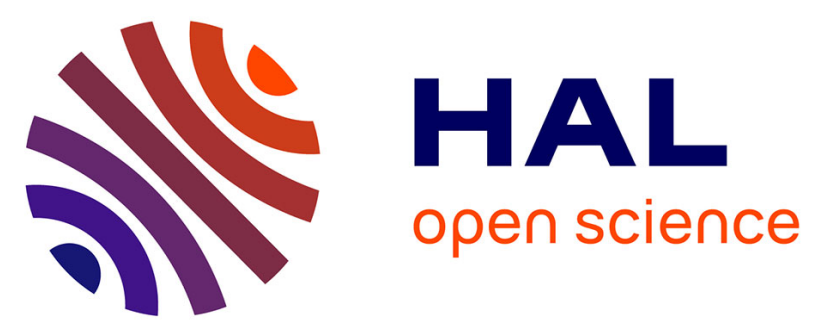

\title{
Wireless Sensing and Identification of Passive Electromagnetic Sensors based on Millimetre-wave FMCW RADAR
}

Hervé Aubert, Franck Chebila, Mohamed Mehdi Jatlaoui, Trang Thai, Hamida Hallil, Anya Traille, Sofiene Bouaziz, Ayoub Rifai, Patrick Pons, Philippe Menini, et al.

\section{To cite this version:}

Hervé Aubert, Franck Chebila, Mohamed Mehdi Jatlaoui, Trang Thai, Hamida Hallil, et al.. Wireless Sensing and Identification of Passive Electromagnetic Sensors based on Millimetre-wave FMCW RADAR. IEEE RFID Technology \& Applications, Nov 2012, Nice, France. 5p. hal-00796002

\section{HAL Id: hal-00796002 https://hal.science/hal-00796002}

Submitted on 1 Mar 2013

HAL is a multi-disciplinary open access archive for the deposit and dissemination of scientific research documents, whether they are published or not. The documents may come from teaching and research institutions in France or abroad, or from public or private research centers.
L'archive ouverte pluridisciplinaire HAL, est destinée au dépôt et à la diffusion de documents scientifiques de niveau recherche, publiés ou non, émanant des établissements d'enseignement et de recherche français ou étrangers, des laboratoires publics ou privés. 


\title{
Wireless Sensing and Identification of Passive Electromagnetic Sensors based on Millimetre-wave FMCW RADAR
}

\author{
H. AUBERT, Senior Member, IEEE, F. CHEBILA, M. JATLAOUI, T. THAI, H. HALLIL, \\ A. TRAILLE, S. BOUAZIZ, A. RIFAÏ, P. PONS, P. MENINI, M. TENTZERIS, Fellow, IEEE
}

\begin{abstract}
The wireless measurement of various physical quantities from the analysis of the RADAR Cross Sections variability of passive electromagnetic sensors is presented. A millimetre-wave Frequency-Modulated Continuous-Wave RADAR is used for both remote sensing and wireless identification of sensors. Long reading ranges (up to some decameters) may be reached at the expense of poor measurement resolution (typically $10 \%$ ).
\end{abstract}

\section{INTRODUCTION}

$\mathrm{T}$ he wireless measurement of a physical quantity from the analysis of the RADAR Cross Section (RCS) variability of passive sensors was proposed for the first time by the authors in 2008 [1] while the proof-of-concept was demonstrated in 2010 [2]. A Frequency-Modulated Continuous-Wave (FMCW) RADAR was used for the measurement of pressure-dependent RCS variation and for the remote derivation of the applied pressure changes. The wireless sensing technique based on RCS-variability measurement has been successfully applied to the remote estimation of other physical quantities, such as temperature [3]-[7]. We have not found reports published before our first papers [1][2] where the physical quantity is directly used for the RCS amplitude modulation of passive electromagnetic (EM) sensors and then remotely measured from FMCW RADAR interrogation. Recently Mandel et al. [8] has reported a very similar technique applied to strain sensors.

The wireless identification of passive and chipless EM sensors may be based on multi-band microwave resonators for encoding data into a specific spectral signature or microwave barcode [9]-[11]. By using an Ultra-WideBand (UWB) interrogator, such barcode may be remotely read. An alternative approach consists of creating a low-frequency barcode in the beat frequency (or Intermediate Frequency)

H. AUBERT, F. CHEBILA, A. TRAILLE, S. BOUAZIZ, A. RIFAÏ, P. PONS and P. MENINI are with LAAS-CNRS, 7 avenue du Colonel Roche, F31077 Toulouse, France and University of Toulouse; UPS, INSA, INP, ISAE; F-31077 Toulouse, France; M. JATLAOUI is currently with IPDIA, 2 rue de la Girafe, 14000 Caen, France, and was with LAAS-CNRS when working on passive pressure EM sensors ; H. HALLIL is currently with University of Bordeaux, Laboratory IMS, CNRS UMR 5218, IPB, Univ. Bordeaux 1, Talence, France and was with LAAS-CNRS when working on passive gas and temperature sensors, T. THAI is with School of ECE, Georgia Institute of Technology, Atlanta, GA 30332, U.S.A and was also with LAAS-CNRS when working on passive temperature and strain EM sensors; M. TENTZERIS is with School of ECE, Georgia Institute of Technology, Atlanta, GA 30332, U.S.A. spectrum synthesized by the FMCW RADAR [12]. The wireless identification of sensors may then be based on FMCW RADAR measurement of the time-arrivals of multiple echoes controlled by delay lines. This approach features the advantage of eliminating the challenging fabrication of UWB readers requiring, e.g., an Analog-toDigital Converter with very high sampling rate. Our wireless system uses the same FMCW RADAR reader for both remote sensing and sensors identification. As shown in this communication it is convenient for long reading ranges (up to some decameters) but does not yield, at least in its present version, to high measurement resolution of physical quantities.

\section{PASsive ChIPless DeVICES For WIRELESS SENSING}

Passive (battery-less) and wireless sensors are very good candidates for measuring physical quantities in harsh environment (e.g., high radiation or extreme temperature) and/or for applications requiring sensing devices with lowcost of fabrication, small size and long-term measurement stability. In 2007 the authors report the first passive pressure sensing device based on an electromagnetic (EM) transduction [13]. The EM sensing device converts the variation of an applied pressure into a variation of millimetre-wave resonant frequency of a resonator. In general passive EM sensing devices convert the variation of a physical quantity (such as, e.g., pressure or temperature) into a known/specific variation of a given electromagnetic wave descriptor. These devices are battery-free and chipless. Based on the EM transduction the first gas sensor was presented in 2004 by Grath et al. [14] and the first strain sensor was reported in 2005 by Chuang et al. [15]. Unlike devices based on Surface Acoustic Waves (see, e.g., [16][19]) EM sensing devices do not require electromagnetic-toacoustic wave conversion and consequently avoid high losses involved in this conversion (the survey of original passive EM sensing devices developed by the authors since 2007 is reported in [20]).

The remote sensing technique based on the RCS variability measurement described in the next Section is applied, for illustration purposes, to a passive EM pressuresensing device. This device is composed of a high resistivity silicon membrane and a planar half-wavelength resonator deposited inside a circular Pyrex cavity (see Figure 1). The membrane and the resonator are separated by a thin air slab. 
Electromagnetic coupling between the resonant mode in the planar resonator and the transverse stationary waves in the dielectric membrane takes place through the evanescent transverse EM field in the air slab. A pressure force applied to the membrane generates a deflection, modifies the air slab thickness, which consequently alters the electromagnetic coupling. As a result the resonant frequency of the sensing device is shifted $(\sim 1 \mathrm{GHz} / \mu \mathrm{m}$ between $0.25 \mu \mathrm{m}$ and $6 \mu \mathrm{m}$ [21]). High sensitivity of the resonant frequency to the applied pressure may be obtained due to the abrupt spatial variation of the transverse evanescent EM field in the air slab. The sensor exhibits a measured sensitivity of $370 \mathrm{MHz} / \mathrm{bar}$ between 0 to 3 bars [22].

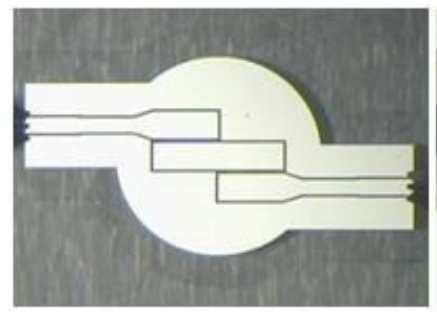

(a)

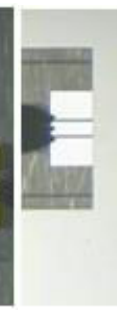

(b)
Fig. 1 : The first passive pressure-sensing device based on electromagnetic transduction and operating in the millimetre-wave frequency range (dimensions: $3,8 \mathrm{~mm} \times 5,8 \mathrm{~mm} \times 1,4 \mathrm{~mm}$ ): (a) top view of the planar halfwavelength resonator deposited inside a circular Pyrex cavity and (b) top view of the high resistivity silicon membrane placed at the top of the planar resonator.

III. REMOTE READING AND IDENTIFICATION OF PASSIVE EM SENSORS BASED ON THE RCSS VARIABILITY MEASUREMENT

A solution for the remote sensing and wireless identification of passive and chipless sensors in a wireless network consists of allocating a unique and controlled spectral distribution of RCSs to each sensor. Such specific RCSs distribution may be used as a signature of the sensor, as proposed in [9][10] while analyzing the RCS variation at a particular frequency -or else, tracking the frequency for which the RCS is maximum- allows in principle the remote derivation of the physical quantity fluctuation [23][24]. An illustrative example of passive sensors having specific and reconfigurable RCSs can be found in [25]. Spectral barcodes are created in [9]-[11] by using multiple resonant frequencies in the microwave frequency range. An alternative approach consists of creating the spectral barcode at low-frequency range, i.e., in the beat frequency (or Intermediate Frequency) spectrum synthesized by the FMCW RADAR [12]. This remote wireless technique is described in the next sections.

\section{A. Remote Sensing based on FMCW RADAR Reader}

In FMCW RADAR, the transmitted signal (transmitted power $P_{T}$ ) or chirp has a linear sawtooth variation of frequency with time. For such modulation the frequency is tuned linearly as a function of time by using a VoltageControlled Oscillator (VCO). The chirp of carrier frequency $f$, bandwidth (or excursion frequency) $\Delta F$ and sawtooth modulation period $T_{R}$ is radiated by using a transmitting antenna (gain $G_{T}$ ) and is back-scattered by the target or scatterer. In free-space the back-scattered signal or echo consists of an attenuated replica of the chirp delayed by the two-way propagation delay $\Delta t=2 R / c$ where $R$ designates the range and $c$ denotes the vacuum celerity of light. The instantaneous frequency difference between the chirp and its delayed replica is constant and given by $2 \Delta F \Delta t / T_{R}$. In order to measure this difference and deriving the range $R$ the echo received by the RADAR receiving antenna $\left(\right.$ Gain $G_{R}$ ) is mixed with the transmitted chirp (homodyne principle). An Analog-to-Digital conversion and Fast Fourier Transform by Hamming windowing at the mixer output signal are finally performed for obtaining the beat frequency-or Intermediate Frequency- spectrum. A millimetre-wave carrier frequency for the FMCW RADAR is preferred here to a lower frequency. As a matter of fact, higher frequencies allow for reducing the sensor and antenna sizes and/or designing directional (high gain) antennas for beamforming, multibeam (for increasing interrogation beam width) or beamsteering RADAR reader. Moreover, higher frequency improves the sensor immunity to objects located at its vicinity by increasing the electrical length separation distance to them. Additionally using millimetre-wave carrier frequency offers high bandwidth $\Delta F$ : as range resolution scales as $1 / \Delta F$, higher bandwidth enables spread-spectrum for identification of greater number of sensors in a wireless network. In the proof-on-concept experiment dated on 2010 [2], a millimetre-wave FMCW RADAR operating at $f=29,45 \mathrm{GHz}\left(\Delta F=650 \mathrm{MHz}, T_{R}=1 \mathrm{~ms}, P_{T}=13 \mathrm{dBm}=20 \mathrm{~mW}\right.$, $G_{T}=14 \mathrm{~dB}$ and $\left.G_{R}=14 \mathrm{~dB}\right)$ is used for the remote derivation of applied pressure from the measurement of the RCS of passive sensor. Such sensor was composed of an antenna (Gain $G_{A}=20 \mathrm{~dB}$ at the carrier frequency) connected to a $50 \Omega$ coaxial cable of physical length $L=1 \mathrm{~m}$ and relative permittivity $\varepsilon_{r}=1,7$ (or refractive index $n=1,3$ ), which is in turn connected to one port of the pressure EM sensing device described in Section II. This cable could be replaced by a millimetre-wave delay line providing a propagation delay of $4,3 n s$ at the carrier frequency over a $2 \%$ bandwidth. The other port of the sensing device is loaded by $50 \Omega$. The transmitted chirp interrogates the sensor, placed at a distance $R=1,4 m$ from the RADAR antennas, at a frequency near the resonant frequency of the sensing device. The pressure is applied on sensing device via a nozzle placed at $40 \mu \mathrm{m}$ high from the thin sensing device membrane.

Figure 2 displays the beat frequency spectrum synthesized by the millimetre-wave FMCW RADAR reader when no pressure is applied. As expected this spectrum exhibits two spikes or echoes at specific frequencies: at the beat frequency $f_{s t r}=12 K H z \approx 2\left(\Delta F / T_{R}\right)(2 R / c)$, the echo level $A_{\text {str }}$ corresponds to the backscattering from the sensor antenna while the second echo level $A_{\text {ant }}$ occurring at a beat frequency $f_{\text {ant }}=24 \mathrm{KHz} \approx 2\left(\Delta F / T_{R}\right)[2(R+n L) / c]$ is associated with the reflection of the millimetre wave on the sensing 
device after reception by the sensor antenna and propagation inside the coaxial cable.

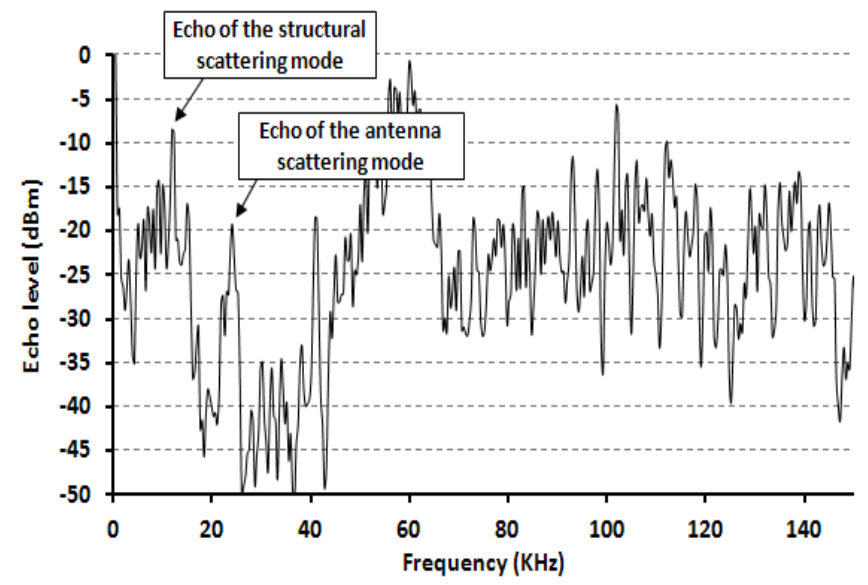

Fig. 2: Measured beat frequency spectrum synthesized by the RADAR reader when the pressure is not applied on the sensing device

As displayed in Figure 3 the echo level $A_{\text {str }}$ does not depend on the applied pressure (the echo level accuracy is estimated at $\pm 0,5 \mathrm{~dB}$ ) and is called the structural scattering mode: it is not useful for the remote measurement of the applied pressure but the corresponding beat frequency $f_{\text {str }}$ allows the remote derivation of the sensor range with a resolution $\mathrm{c} / 2 \Delta F \approx 23 \mathrm{~cm}$.

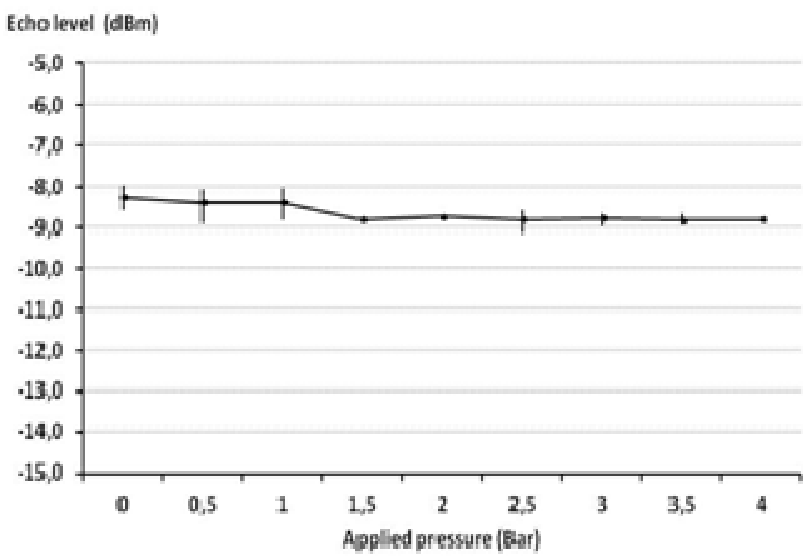

Fig. 3: Measured echo level of passive EM pressure sensor versus applied pressure at the beat frequency $f_{\text {str }}$ of the structural scattering mode.

Moreover, as shown in Figure 4, the echo level $A_{\text {ant }}$ depends on the applied pressure. It is called the antenna scattering mode. Between 0 and 2.5bars the measured sensitivity is $0.8 \mathrm{dBm} / \mathrm{bar}$. The full-scale echo measurement range is $5 \mathrm{dBm}$ when the applied pressure ranges from 0 to 3,5bars. When a pressure is applied on the membrane of the sensing device, the RCS of antenna-scattering-mode is varied, received backscattered power $P_{R}$ changes and as a result echo level $A_{\text {ant }}$ is modified. The measurement of this modification allows, at least in principle, the remote estimation of the applied pressure variation. This summarizes the wireless reading principle based on the FMCW RADAR measurement of sensor-RCS variation. The unambiguous identification of echoes associated with the structural and antenna scattering modes among the multiple spikes in the beat frequency spectrum (as shown in Figure 2) is possible only for sensor having a structural-scattering-mode RCS sufficiently high, that is, providing an echo $A_{\text {str }}$ significantly higher than the other peaks. It is the limitation of the proposed technique in its present form. The beat frequency $f_{\text {str }}$ can then be derived and since the delay between the structural- and antennascattering-modes is known (fixed by the delay line), the location in the spectrum of the antenna-scattering-mode beat frequency $f_{\text {ant }}$ can be deduced.

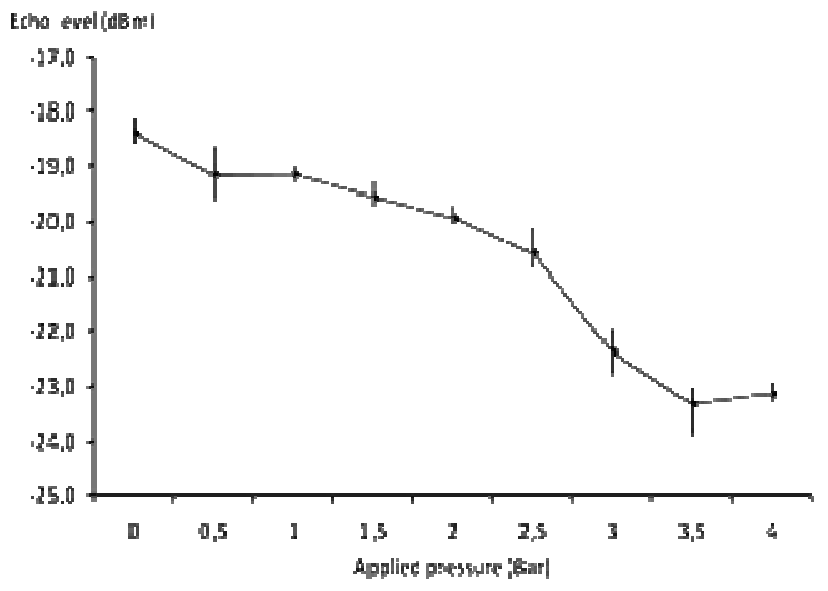

Fig. 4: Measured echo level of passive EM pressure sensor versus applied pressure at the beat frequency $f_{\text {ant }}$ of the antenna scattering mode.

Following the proposed remote sensing technique based on RCS-variability measurement, the passive EM sensor yields to a full-scale echo measurement range $\Delta A=/ 10 \log _{10}\left(A_{2} / A_{1}\right) /$ (in $\mathrm{dB}$ ) [or equivalently a full scale RCS range $\Delta \sigma=/ \sigma_{2}-\sigma_{1} /($ in $\left.\mathrm{dB})\right]$ for a physical quantity range $\Delta \varphi=/ \varphi_{2}-\varphi_{1} /$. Consider a passive scatterer composed of a horn antenna $\left(G_{\text {horn }}=20 \mathrm{~dB}\right.$ and size $\left.30 \mathrm{~mm} \times 40 \mathrm{~mm}\right)$ loaded by a passive EM having an input impedance of $50 \Omega$ when $\varphi=\varphi_{1}$ and $0 \Omega$ when $\varphi=\varphi_{2}$. The RADAR transmitting antenna operating at $29,75 \mathrm{GHz}$ is a parabolic antenna $\left(G_{T}=35 \mathrm{~dB}\right)$ and the RADAR receiving antenna is horn antenna $\left(G_{R}=14 d B\right)$. The transmitted power is $P_{T}=13 \mathrm{dBm}(20 \mathrm{~mW})$. In this out-door experiment the distance between the RADAR and the loaded scatterer is $R=30 \mathrm{~m}$ (Figure 5). The Figure 6 displays the resulting measured lowfrequency spectrum provided by the millimetre-wave FMCW RADAR reader when $\varphi=\varphi_{1}$ and $\varphi=\varphi_{2}$. The sensitivity of the reader or minimum detectable received power is $-70 \mathrm{dBm}$. At the expected beat frequency $260 \mathrm{kHz} \approx 2\left(\Delta F / T_{R}\right)(2 R / \mathrm{c})$, $\left(\Delta F=650 \mathrm{MHz}\right.$ and $\left.T_{R}=1 \mathrm{~ms}\right)$ a high echo level is observed when $\varphi=\varphi_{2}$. 


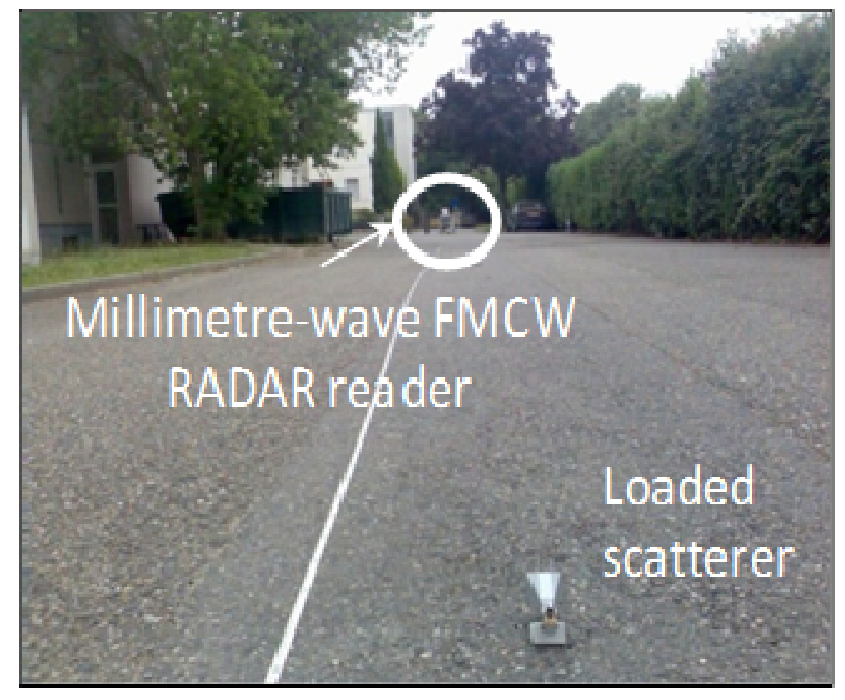

Fig. 5 : Outdoor environment for the measurement of the beat frequency spectrum synthesized by a FMCW RADAR operating at $29,75 \mathrm{GHz}$. The scatterer is placed on the ground surface at $30 \mathrm{~m}$ from the RADAR.

A low but still measurable echo level of $-48 \mathrm{dBm}$ (just above the noise level $A_{\text {noise }} \approx-50 \mathrm{dBm}$ ) is measured when $\varphi=\varphi_{1}$ (as expected, if the scatterer is removed or is moved away from the RADAR, this echo level disappears at $260 \mathrm{kHz}$ ). The fullscale measurement range at $30 \mathrm{~m}$ is then found to be $\triangle A=10 d B$. Since the accuracy on the echo level measurement is here $\delta A \sim 1 d B$, the resulting resolution $\delta A / \Delta A$ is low (approximately 10\%). SAW devices sensors offer high measurement resolution but with reading range significantly lower.

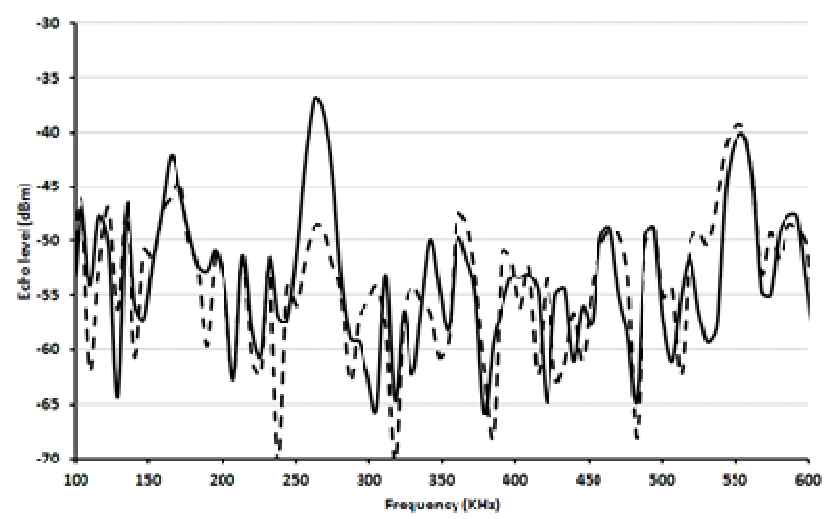

Fig. 6 : Measured beat frequency spectrum in the out-door environment shown in Fig. 4 for two values of the physical quantity $\varphi$ : - - - for $\varphi=\varphi_{1}$ (or equivalently, the scatterer is loaded by $50 \Omega$ ); - for $\varphi=\varphi_{2}$ (or equivalently, the scatterer is short-circuited);

\section{B. Remote Identification of Passive EM Sensors using FMCW RADAR Reader}

The FMCW-RADAR reader used for the remote reading of passive sensors can also be utilized for identification purposes. When the passive sensor is composed of an antenna connected to a transmission line (or delay line) which loads in turn the sensing device, the measurement of the difference between the beat frequencies of the antennascattering-mode $f_{\text {ant }}$ and structural-scattering-mode $f_{s t}$ allows the remote estimation of the transmission line electrical length (or propagation delay). By allocating a specific electrical length (or delay) to each sensor in a wireless network, this simple measurement may be used, at least in principle, for identification purpose. In the proof-of-concept experiment reported recently by the authors in [12] the identification is based on an antenna connected to multiple transmission lines, each being loaded by various fixed impedances. All transmission lines used in this experiment

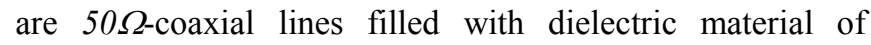
relative permittivity $\varepsilon_{r}=1,7$ and having $2 \mathrm{~dB} / \mathrm{m}$ of losses. The set up is composed of two horn antennas at distances $R_{I}=1 \mathrm{~m}$ and $R_{2}=2,5 m$ from the RADAR antennas (see Figure 7).

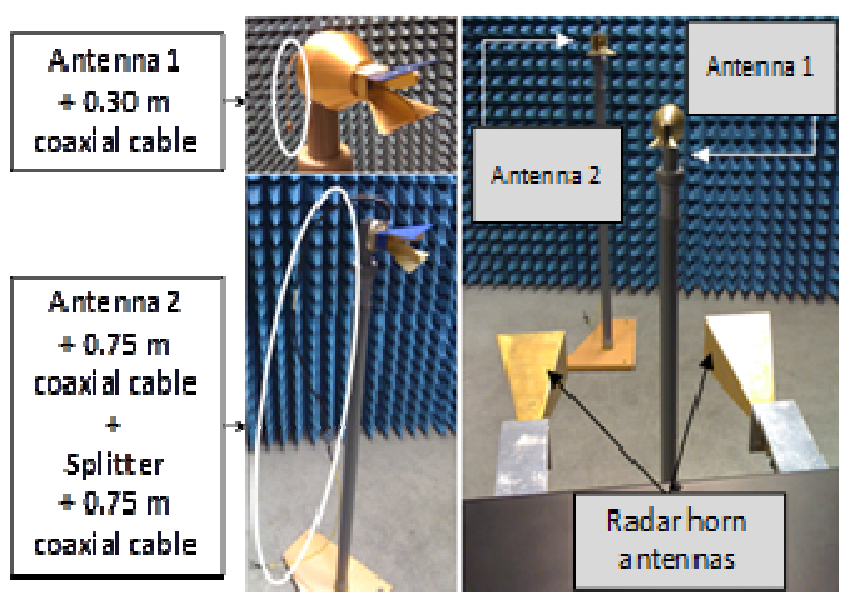

(a)

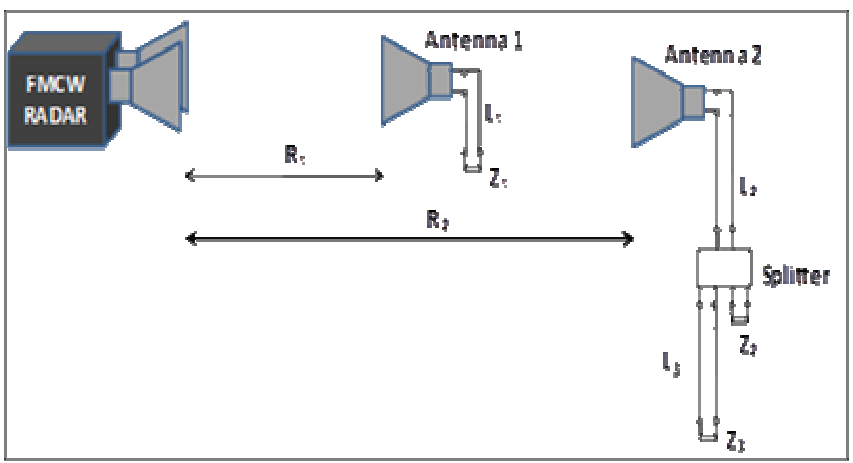

(b)

Fig. 7 : (a) Proof-of-concept set-up for demonstrating the feasibility of the wireless identification of passive sensors based on the millimetre-wave FMCW-RADAR used for remote sensing and (b) Schematic of the experimental set-up (the load impedance $Z_{1}, Z_{2}$ and $Z_{3}$ are infinite).

One horn antenna is connected to a coaxial cable denoted by cable 1 of physical length $L_{1}=30 \mathrm{~cm}$ which is loaded by an open-circuit (the load impedance $Z_{l}$ is infinite). The second horn antenna is connected to a coaxial cable denoted by cable 2 of physical length $L_{2}=75 \mathrm{~cm}$. This cable is in turn connected to the input port of a splitter. One splitter output is directly connected to an open-circuit (the load impedance $Z_{2}$ is infinite) while the second output is connected to a coaxial 
cable (cable 3 ) of physical length $L_{3}=75 \mathrm{~cm}$ which is loaded by an open-circuit (the load impedance $Z_{3}$ is infinite). Figure 8 displays the resulting beat frequency spectrum synthesized by the millimetre-wave FMCW RADAR Reader $\left(f=29,75 \mathrm{GHz}, \Delta F=700 \mathrm{MHz}\right.$ and $\left.T_{R}=1 \mathrm{~ms}\right)$. As expected five echoes are detected in this spectrum: two echoes (at $9 \mathrm{KHz}$ and $23 \mathrm{KHz}$ ) correspond to the time-arrivals of structural scattering mode of the two horn antennas while the three others (at $14 \mathrm{KHz}, 33 \mathrm{KHz}$ and $43 \mathrm{KHz}$ ) are associated with the reflection of the millimetre-wave on the loads $Z_{1}, Z_{2}$ and $Z_{3}$. The unique and controlled distribution of these peaks can then be advantageously used for the remote identification of the scatterer.

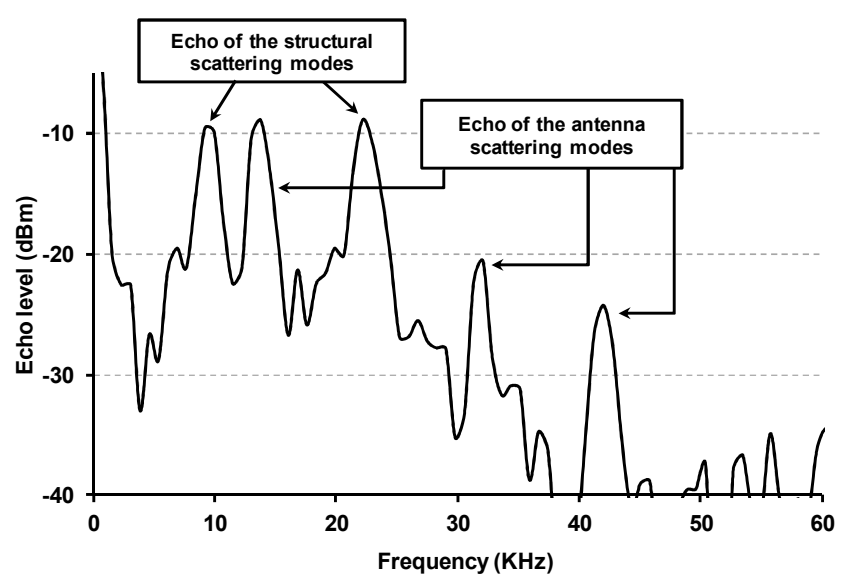

Fig. 8 : Beat frequency spectrum synthesized by the millimetre-wave FMCW RADAR Reader when interrogating the scatterer shown in Fig. 5

\section{CONCLUSION}

The use of a millimetre-wave FMCW Radar reader for both the wireless reading and identification of passive EM sensors has been presented in this communication. It is shown that the wireless measurement of various physical quantities is possible from the analysis of the RADAR Cross Sections variability of passive electromagnetic sensors. Additionally the same FMCW RADAR can be used for identifying the passive sensors in a wireless network. However, the measurement resolution is poor (typically $10 \%$ of the full-scale measurement range). An alternative solution would consist of tracking in the beat frequency spectrum the frequency at which the RCS reaches its maximum value as the physical quantity varies [24][26]. This solution, under investigation by the authors, may achieve higher measurement resolution while not significantly alters the reading range.

\section{ACKNOWLEDGMENTS}

The authors wish to thank the two following institutions for financial support: the French Radioactive Waste Management Agency (ANDRA) through the contract $\mathrm{N}^{\circ}$
045985 and the Pole de Competitivité Aéronautique, Espace et Systèmes Embarqués (AESE) through the projet Système Autonome Communicant En Réseau (SACER).

\section{REFERENCES}

[1] JATLAOUI, M., CHEBILA, F., PONS, P., AUBERT, H.: Pressure Sensing Approach Based on Electromagnetic Transduction Principle. Asia Pacific Microwave Conference, Hong Kong and Macao, China (2008).

[2] CHEBilla, F., JATlaOUi, M., PONS, P., AUBERT, H.: Pressure Measurement from the RADAR Interrogation of Passive Sensors. IEEE International Symposium on Antennas Propagat., Toronto, Ontario, Canada (2010).

[3] THAi, T.-T., CHEBILA, F., JATlAOUI, M., PONS, P., AUBERT, H., DEJEAN, G.R., TENTZERIS, M.M., PLANA, R.: A Novel Passive Ultrasensitive RF Temperature Transducer for Remote Sensing and Identification utilizing RADAR Cross Sections Variability. IEEE Antennas and Propagation Symposium, Toronto, Ontario, Canada (2010).

[4] THAI, T.-T., CHEBILA, F., JATlAOUI, M., PONS, P., AUBERT, H., DEJEAN, G.R., TENTZERIS, M., PLANA, R.: Design and Development of a Millimetre-wave Novel Passive Ultrasensitive Temperature Transducer for Remote Sensing and Identification. European Microwave Week, Paris, France (2010).

[5] THAi, T.-T., JATlAOUI, M., CHEBILA, F., AUBERT, H., PONS, P., DEJEAN, G.R., TENTZERIS, M., PLANA, R.: Design and Development of a Novel Passive Wireless Ultrasensitive RF Temperature Transducer for Remote Sensing. IEEE Sensors Journal, in press (2012).

[6] TRAILlE, A., BOUAZIZ, S., AUBERT, H., PONS, P., TENTZERIS, M.: A Novel Wireless Passive Temperature Sensor Utilizing Microfluidic Principles in Millimeter-Wave Frequencies. IEEE sensors Conference, Limerick, Ireland, pp 524 - 525 (2011).

[7] Traille, A., BOUAZIZ, S., PINON, S., PONS, P., AUBERT, H., BOUKABACHE, A., TENTZERIS, M.: A Wireless Passive RCSbased Temperature Sensor using Liquid Metal and Microfluidics Technologies. European Microwave Week, Manchester (2011).

[8] MANDEL, C., SCHÜßLER, M., JAKOBY, R.: A Wireless Passive Strain Sensor. IEEE sensors Conference, Limerick, Ireland, pp. $2007-$ 2010 (2011).

[9] JALALY, I., ROBERTSON, D.: Capacitively-tuned split microstrip resonators for RFID barcodes. Eur. Microw. Conf., Paris, France, vol. 2, pp. 4-7 (2005).

[10] McVAY, J., HOORFAR, A., ENGHETA, N.: Space-filling curve RFID tags. IEEE Radio Wireless Symp., San Diego, CA, pp. 199-20 (2006).

[11] PRERADOVIC, S., BALBIN, I., KARMAKAR, N.C., SWIEGERS, G.: Multiresonator-Based Chipless RFID System for Low-Cost Item Tracking. IEEE Transactions on Microwave Theory and Techniques, vol. 57, No. 5, pp. 1411-1419 (2009).

[12] JATLAOUI, M., CHEBILA, F., BOUAZIZ, S., PONS, P., AUBERT, H.: Original Identification technique of passive EM Sensors using Loaded Transmission Delay Lines. European Microwave Week, Paris, France (2010).

[13] JATLAOUI, M., PONS, P., AUBERT, H.: Radio-Frequency pressure transducer. European Microwave Conference, München, Germany, pp. 983-986 (2007).

[14] MCGRATH, M., SABOUNI, R., PHAM, A.: Development of nanobased resonator gas sensors for wireless sensing systems. Proceedings of the SPIE, vol. 5593, No 1, pp. 62-72 (2004)

[15] CHUANG, J., THOMSON, D.J., BRIDGES, G.E.: Embeddable wireless strain sensor based on resonant RF cavities. Review of Scientific Instruments, DOI: 10.1063/1.2051808.

[16] BUFF, W., KLETT, S., RUSKO, M., EHRENPFORDT, J., GOROLI, M.: Passive remote sensing for temperature and pressure using SAW resonator devices. IEEE Transactions on Ultrasonics, Ferroelectrics and Frequency Control, vol. 45, No. 5, pp. 1388 - 1392 (1998). 
[17] VARADAN, V.K., TEO, P.T., JOSE, K.A., VARADAN, V.V.: Design and development of a smart wireless system for passive temperature sensors. Smart Materials and Structures, vol. 9, No 4, pp. 379-388 (2000)

[18] POHL, A.: A Review of Wireless SAW Sensors. IEEE Transactions on Ultrasonics, Ferroelectrics, and Frequency Control, vol. 47, No. 2, pp.317-332 (2000)

[19] PEREIRA, M., LAD, R.J., DAVUlis, P., CANABAL, A., MOONLIGHT, T., MOULZOLF, S., FRANKEL, D.J., POLLARD, T., McCANN, D., DUDZIK, E., ABEDI, A., HUMMELS, D., BERNHARDT, G., Wireless Acoustic Wave Sensors and Systems for Harsh Environment Applications. Wireless Sensors and Sensor Networks Conference, Phoenix, USA, pp.41-44 (2011).

[20] PONS, P., AUBERT, H., MENINI, P., TENTZERIS, M.: Electromagnetic transduction for wireless passive sensors. Proceedings Eurosensors XXVI, Kraków, Poland (2012).

[21] JATlAOUI, M., PONS, P., AUBERT, H.: Pressure Micro-sensor based on Radio-Frequency Transducer. IEEE International Microwave Symposium, Atlanta, Georgia, USA, pp. 1203-1206 (2008).

[22] JATLAOUI, M., CHEBILA, F., GMATI, I., PONS, P., AUBERT, H.: New Electromagnetic Transduction Micro-sensor Concept For Passive Wireless Pressure Monitoring Application. Transducers, $15^{\text {th }}$ International Conference on Solid-State Sensors, Actuators and Microsystems, Denver, Colorado, USA, pp. 1742-1745 (2009).

[23] JATlaOU,, M., CHEBILA, F., PONS, P., AUBERT, H.: New Micro-sensors Identification Techniques Based on Reconfigurable Multi-band Scatterers. Asia-Pacific Microwave Conference, Singapore (2009).

[24] AUBERT, H., PONS, P., CHEBILA, F., JATLAOUI, M. : Measurement Device Comprising an Electromagnetic Diffuser, Patent WO 2010/136388, May 29, 2009.

[25] CHEBILA, F., JATlAOUI, M., PONS, P., AUBERT, H.: Reconfigurable Multi-band Scatterers for Micro-sensors Identification. IEEE International Symposium on Antennas Propagat., Charleston, South Carolina, USA (2009).

[26] JATLAOUI, M., CHEBILA, F., PONS, P., AUBERT, H.: Wireless Interrogation Techniques for a Passive Pressure Micro-sensor using an EM Transducer. European Microwave Week, Nuova Fiera di Roma, Rome, Italy (2009). 